\title{
AVALIAÇÃO DA APRENDIZAGEM NA BNCC PARA LINGUAGENS E SUAS TECNOLOGIAS: UM ESTUDO INTERPRETATIVO
}

\author{
EVALUATION OF LEARNING AT BNCC FOR \\ LANGUAGES AND THEIR TECHNOLOGIES: AN \\ INTERPRETATIVE STUDY
}

\author{
André Luiz Santos Praxedes" \\ Silvio Nunes da Silva Júnior ${ }^{* *}$ \\ Rita de Cássia Souto Maior \\ Geison Araújo Silva ${ }^{* * * * *}$
}

Resumo: Este estudo propõe uma reflexão acerca da avaliação da aprendizagem de língua portuguesa na Base Nacional Comum Curricular (BNCC) para linguagens e suas tecnologias no Ensino Médio. Para este fim, traça-se um aparato teórico que envolve a perspectiva dialógica da linguagem, as considerações sobre ensino e escola reflexivos, bem como os olhares antigos e atuais sobre a avaliação. Em linhas gerais, observou-se que a avaliação da aprendizagem está presente na BNCC a partir de outros termos, como análise crítica, decisões orientadas, compreensão, valores e configurações sociais, e que os estudos dialógicos, principalmente no tocante à noção de alteridade, integram indiretamente as concepções de linguagem e avaliação do documento.

Palavras-chave: avaliação da aprendizagem; perspectiva dialógica; BNCC.

\footnotetext{
"Graduado em Letras/Português pela Faculdade de Letras da Universidade Federal de Alagoas (FALE/UFAL). Docente da rede privada de ensino, em Maceió/AL. Membro do GEDEALL/CNPq/UFAL.E-mail: andre.praxedes@fale.ufal.br.

** Doutor em Linguística pelo Programa de Pós-graduação em Linguística e Literatura da Universidade Federal de Alagoas (PPGLL/UFAL). Estágio pós-doutoral no Programa de Pós-graduação Mestrado em Educação, Cultura e Territórios Semiáridos da Universidade do Estado da Bahia (PPGESA/UNEB). Pesquisador do GEDEALL/CNPq/UFAL. Professor efetivo da SEMEDE/Palmeira dos Índios e professor substituto da FALE/UFAL e da Universidade de Pernambuco (UPE/ Garanhuns). E-mail: silvio.junior@fale.ufal.br.

**** Doutora em Linguística pelo Programa de Pós-graduação em Linguística e Literatura da Universidade Federal de Alagoas (PPGLL/UFAL). Estágio pós-doutoral no Programa de Pós-graduação em Linguística da Universidade Federal do Ceará (PPGL/UFC). Líder do GEDEALL/CNPq/UFAL. Professora da graduação e da pós-graduação (PPGLL) da FALE/ UFAL. E-mail: rita.lima@fale.ufal.br.

***** Mestrando em Linguística pelo Programa de Pós-graduação em Linguística e Literatura da Universidade Federal de Alagoas (PPGLL/UFAL). Membro do GEDEALL/CNPq/UFAL. Editor-Chefe da Editora Diálogos. E-mail: geison-araujo@ hotmail.com.
} 


\begin{abstract}
This study proposes a reflection on the assessment of Portuguese language learning in the Common National Curriculum Base (BNCC) for languages and their technologies in high school. To this end, a theoretical apparatus is drawn that involves the dialogical perspective of language, considerations on reflective teaching and school, as well as old and current views on assessment. In general terms, it was observed that the assessment of learning is present in the BNCC from other terms, such as critical analysis, guided decisions, understanding, values and social configurations, and that dialogical studies, especially with regard to the notion of otherness, indirectly integrate the concepts of language and evaluation of the document.
\end{abstract}

KEYworDs: learning assessment; dialogic perspective; BNCC.

\title{
CONSIDERAÇÕES INICIAIS
}

Dentro de uma Linguística Aplicada transdisciplinar (MOITA LOPES, 2006; ZOZZOLI, 2020), pautada na perspectiva da desaprendizagem (FABRÍCIO, 2006), que defende uma educação escolar que caminha em busca de um paradigma reflexivo (ALARCÃO, 2001) e processual, temas como a avaliação da aprendizagem se tornam importantes de serem discutidos diante das tantas exigências que norteiam a atividade docente, especialmente no que diz respeito ao trabalho pedagógico com a língua portuguesa (doravante LP), já que se utiliza a língua para o aprendizado sobre ela mesma. Documentos oficiais (BRASIL, 2006, 1998) vêm tentando apontar pressupostos teóricos e metodológicos que podem auxiliar de alguma forma o trabalho pedagógico nas salas de aula de LP de todo o país. No entanto, viabilizando as transformações sociais que afetam todos os setores na atualidade, inclusive a educação, percebe-se que a avaliação e diversos outros elementos do campo pedagógico precisam ter seus sentidos reelaborados no intuito de inserir novas perspectivas educacionais, linguísticas e literárias no seio de uma contemporaneidade que, segundo Moita Lopes (2006), promove grande ebulição sociocultural político-histórico e epistemológica que afeta profundamente o modo de viver e pensar das comunidades, e que, conforme Fabrício (2006, p. 47), "torna problemática a adoção de pontos de vista e explicações causais simplistas a respeito dos fenômenos sociais".

Em função dessas mudanças, a Base Nacional Comum Curricular (BNCC), lançada em 2018, surge com o objetivo de rever os referenciais para o ensino que predominam desde a década de 1990, quando os Parâmetros Curriculares Nacionais (PCNs) foram publicados. Para uma observação mais direta de como ocorreu o remodelamento das reflexões anteriores, este estudo busca investigar como a BNCC para linguagens e suas tecnologias no ensino médio trata a avaliação da aprendizagem, apontando as relações que o tema tem com a concepção de língua/linguagem prezada pelo documento, questionando: De que modo a avaliação é tratada na BNCC de língua portuguesa para o ensino médio? Como a concepção de língua/linguagem 
prezada pelo documento contribui para as práticas avaliativas mediadoras na educação básica? De que forma os processos avaliativos dialogam com as propostas gerais da BNCC?

Com isso, dispõe-se de uma abordagem teórica pautada pela discussão sobre língua/ linguagem na perspectiva dialógica (VOLÓCHINOV, 2017; BAKHTIN, 2012, 2003), que pressupõe a construção dos sujeitos e do mundo por meio do diálogo social; da escola reflexiva (ALARCÃO, 2001, 2011), que assume a missão social de mediar o desenvolvimento humano crítico; da avaliação da aprendizagem (CARMINATTI, BORGES, 2012; GOERGEN, 1997; LUCKESI, 2011), que abarca a avaliação mediadora (HOFFMAN, 2014), preocupadas em direcionar seus olhares em função da necessidade de se refletir sobre o processo de aprendizagem e não dos resultados abstratos priorizados pelas práticas tradicionais de ensino.

Na metodologia deste trabalho, discute-se sobre a abordagem qualitativa de pesquisa, a qual se distancia da visão positivista defendida pelos pressupostos quantitativos, numa perspectiva histórico-interpretavista, que, calcada numa dimensão que se preocupa em interpretar o modo como os meios sociais, culturais, geográficos e econômicos, constroem o mundo social, seus sentidos e sua história (SOUTO MAIOR, 2020). Pela abordagem histórica, busca-se contextualizar os sentidos microestruturalmente, revendo narrativas do cotidiano e seus sentidos partilhados, num corte interpretativista dos discursos, e macroestruturalmente, retomando crenças, documentos e registros oficiais desses sentidos, também em um viés de interpretação.

Dentro dessa abordagem, o estudo se embasa, também, na vertente documental, quando o pesquisador se pergunta acerca de quem produziu um documento, para quem, com que objetivo, quais as intenções institucionais com a produção do documento etc. (FLICK, $2004^{1}$ ), uma vez que se buscará construir um diálogo entre o contexto macro e micro social e as questões teóricas da BNCC. Tal empreendimento é desenvolvido a partir de uma análise que articula trechos do citado documento, que tratam da avaliação da aprendizagem de língua portuguesa, com pressupostos teóricos voltados às temáticas que norteiam este trabalho. Em termos de estruração, o artigo possui, além das considerações iniciais e finais, os tópicos: língua/linguagem, reflexão e avaliação; metodologia da pesquisa documental; e avaliação da aprendizagem de língua portuguesa na BNCC.

\section{LÍNGUA/LINGUAGEM, REFLEXÃO E AVALIAÇÃo}

Para dar conta dos objetivos já pontuados e encaminhar reflexões a partir das questões de pesquisa, o aparato teórico do trabalho está estruturado nas discussões de autores que abordam temas como: língua/linguagem na perspectiva dialógica (VOLÓCHINOV, 2017;

\footnotetext{
${ }^{1}$ Para Flick (2004), os documentos não são somente simples dados para recurso de pesquisa. Eles apresentam dimensões que o contextualizam histórico socialmente, conforme será apresentado adiante.
} 
BAKHTIN, 2012, 2003), escola reflexiva (ALARCÃO, 2001, 2011) e avaliação (CARMINATTI; BORGES, 2012; GOERGEN, 1997; LUCKESI, 2011; HOFFMANN, 2014). Tais escolhas teóricas se dão pela necessidade de se mobilizar temas que se complementam, na tentativa de estabelecer uma fundamentação coerente com o que se propõe no estudo.

De modo introdutório, retomamos Volóchinov (2017), quando o autor entende linguagem e sociedade como termos indissociáveis diante da intersecção cotidiana que os dois termos fazem nas reflexões e nas ações dos sujeitos em atividades sociais. Partindo desse pressuposto, observa-se a língua em função da relação entre duas realidades: o caráter de inconclusibilidade intrínseco aos atos de enunciação, únicos e irrepetíveis; e os aspectos finitos e previsíveis, que se adquirem ao longo da vida e que são necessários para a interação. Esses aspectos, por serem frutos do histórico humano, são carregados de sentidos.

Para Volóchinov (2017) e Bakhtin (2012, 2003), para além da expressão do sujeito, o uso da língua também propicia a materialização de significados não imediatos dentro de um sistema de representação social, construído a partir das referências de grupos sociais, o qual Miotello (2014) denomina ideologia. A ideologia, no sentido de reprodução, pode não ser vista como "acontecimento" que constitui e que é constituído nas práticas dialógicas de linguagem, entendendo que, sendo mera reprodução, a construção da subjetividade possuiria uma mão única de "recebimento" de significados, dados pela estrutura social, o que podemos nomear como "noção fantasmagórica de sentidos" (SOUTO MAIOR, 2009). Segundo Lima e Souto Maior (2012, p. 403), "Bakhtin não discute especificamente esse sentido flutuante social, mas trata da noção de ideologia no movimento, assim opõe, de forma não antagônica e excludente, as noções de ideologia do cotidiano e de ideologia oficial”. Ambas as ideologias coexistem nas rupturas e nas linearidades das práticas sociais discursivas.

Considerando que a "língua vive e evolui historicamente na comunicação verbal concreta, não no sistema linguístico abstrato das formas da língua nem no psiquismo individual dos falantes" (VOLÓCHINOV, 2017, p. 124), entende-se que os processos de atividade da linguagem são ininterruptos. Nesse sentido, enquanto um sujeito faz uso de elementos linguístico-discursivos para interagir socialmente, ele está levando em consideração a existência de outros, que, dessa forma, constituem-se mutuamente por meio da linguagem em relações dialógicas de alteridade, as quais consistem em processos de fundamento da identidade, caracterizados pela refração de sentidos durante a situação enunciativa (BAKHTIN, 2003).

Dessa maneira, a sala de aula de língua portuguesa se concebe como um campo discursivo, construído pela e na alteridade, que contribui para as formações de sujeitos responsivos ativos (BAKHTIN, 2003) na sociedade. Nessa linha de atuação, pesquisadores já vêm alertando para abordagens de ensino que não favorecem uma formação ativa do sujeito (ZOZZOLI, 1998, 2016; LIMA; SOUTO MAIOR, 2012; SILVA JÚNIOR, 2021, 2019). Ainda sobre essa problemática, Lima e Souto Maior (2012, p. 200) asseveram que 
temos observado que, no que se refere ao ensino de LP, tem havido vários equívocos no como se ensina, não obstante o para quê se ensina pareça estar em consonância com os objetivos pretendidos e com a concepção de linguagem que adotamos nesse texto. Ou seja, mesmo quando se tem noção do que se pretende, há dissonâncias no fazer pedagógico de alguns professores de LP (LIMA, 2010). O que mais se verifica é a presença de uma gramática descontextualizada, isto é, uma Gramática concebida não na perspectiva do uso da língua, mas na descrição e identificação de suas formas. Dessa forma, os processos de leitura e produção de textos tendem a ficar comprometidos.

Os envolvidos nas práticas de ensino em sala de aula poderiam participar de atividades numa perspectiva dialógica, de modo a implicar suas próprias subjetividades, bem como nas constituições das subjetividades dos outros, a partir das práticas discursivas e da avaliação dessas práticas num continuum temporal a ser ressignificado a todo momento em que os sujeitos atuam no mundo. Para Bakhtin (2003, p. 272),

toda compreensão plena real é ativamente responsiva e não é senão uma fase inicial preparatória da resposta (seja qual for a forma em que ela se dê). $O$ próprio falante está determinado precisamente a essa compreensão ativamente responsiva: ele não espera uma compreensão passiva, por assim dizer, que apenas duble o seu pensamento em voz alheia, mas uma resposta, uma concordância, uma participação, uma objeção, uma execução, etc.

Todo e qualquer discurso é proferido na estima de uma resposta, que, para ser tida como enunciado, precisa carregar também sentido compartilhado, o qual só é perceptível por meio da compreensão do interlocutor. No campo do ensino e aprendizagem, essa noção é importante por atentar para a interação estabelecida em sala de aula, mais especificamente entre professor $\mathrm{x}$ alunos $\mathrm{e}$ aluno $\mathrm{x}$ aluno. Com base no processo denominado responsividade, em que se inclui a compreensão do interlocutor seguida por uma atitude de resposta, é possível refletir se realmente a sala de aula de línguas vem atuando como uma arena propícia para o diálogo social (BAKHTIN, 2003; SILVA JÚNIOR, 2021).

O diálogo social, nesse sentido, é uma cadeia viva e ativa que ultrapassa as classificações teóricas, uma vez que, em sua produção, são articuladas vozes de diversos sujeitos (ZOZZOLI, 2016). A intermediação pedagógica também pressupõe a perspectiva interativa dialógica que, segundo Lima e Souto Maior (2012, p. 400), "não tem atendido à demanda social que requer sujeitos críticos e conscientes do seu papel social". Ainda segundo esses autores, "é necessário [...] que o professor de língua materna configure sua proposta metodológica a uma eficiente concepção de língua que, em sendo criação de sentidos, encarna significados e dá origem à comunicação" (LIMA; SOUTO MAIOR, 2012, p. 401). 
Nessa perspectiva, pensa-se na sala de aula como uma arena responsiva (SILVA JÚNIOR, 2021), uma vez que, nessa conceituação, o contexto de ensino passa a ser visto como um espaço plural que ultrapassa as limitações físicas da instituição, levando em conta toda a dimensão educativa do sujeito, que tem significativa contribuição da mediação pedagógica do professor (SILVA JÚNIOR, 2021). Esse cruzamento de reflexões constantes é orientado "para a ação e é social e política pelo ato de que, em um movimento espiral, o processo de refletir penetra o interior do pensamento, atravessa o processo de pensamento e articula-se ao exterior da situação" (BRZEZINSKI, 2001, p. 72), ou seja, se relaciona com a vida social dos sujeitos, incluindo questões valorativas (VOLÓCHINOV; BAKHTIN, 1926), além dos conteúdos ideológicos, que, de acordo com Volóchinov (2017), representam e substituem algo encontrado fora da sua dimensão, ou, simplesmente, como signos.

A realidade, muitas vezes, institui-se como oposta. Luckesi (2008, p. 17-18) afirma que muitas das práticas pedagógicas brasileiras estão polarizadas pelas provas e exames, o que é chamado pelo autor de pedagogia do exame. Essas práticas fazem com que o elemento de maior interesse dos estudantes e seus familiares seja a nota, uma vez que ela se responsabiliza pelo avanço ou não do estudante às turmas seguintes, o que não corresponde necessariamente à ocorrência de aprendizagem (SOUSA, 1994). A distância entre a nota e a aprendizagem tem sido um elemento muito importante para ser pesquisado, visto que, na prática de ensino visando a aprendizagem, pensar nesta distância é observar as dimensões quantitativas e qualitativas do processo de avaliação. Muitas vezes, as notas são vistas como "redes de segurança em termos do controle exercido pelos professores sobre seus alunos, das escolas e dos pais sobre os professores, do sistema sobre suas escolas" (HOFFMAN, 2014, p. 29), e essa rede de controle se estabelece, por sua vez, pelo controle sobre sentidos.

Relacionado a fatores como capitalismo, globalização e colonialismo, essa necessidade pelo controle, que não promove engajamento com exigências imediatas da transformação social, opõe-se radicalmente ao olhar crítico sob o qual a avaliação da aprendizagem vem sendo submetida. Os resquícios desse embate social - controle vs transformação - que, para Georgen (1997), configuram uma crise identitária pautada na disputa entre a avaliação que segue a lógica do mercado e a avaliação marcada pelo distanciamento crítico, são revelados de diversas formas, como demonstram os abalos estruturais que as sociedades modernas vêm sofrendo ao perceberem seus alicerces sendo reconstruídos por políticas afirmativas responsáveis pela ascensão de grupos com prejuízos históricos diversos, como os queers, os afrodescendentes e as minorias religiosas.

Sob esse viés, considerando aspectos como: o diálogo com o mundo, o compromisso com as vozes do sul e a necessidade de se reconsiderar os modos de produzir ciência e a transformação social (MOITA LOPES, 2006, 2013), as práticas avaliativas mediadoras são pertinentes para que se possa perceber se o ensino de língua portuguesa enfatiza os processos de pensamento dos alunos de modo a intermediar a construção de uma autonomia do estudante, 
necessária para produzir pensamentos participativos ${ }^{2}$ (BAKHTIN, 2012) no contexto da sala de aula. Nesse contexto, é "preciso refletir sobre a vida que [...] se vive, em uma atitude de diálogo com os problemas e as frustrações, os sucessos e os fracassos, mas também em diálogo com o pensamento, o pensamento próprio e o dos outros" (ALARCÃO, 2001, p. 15), uma vez que o sujeito emerge da relação com o outro (BAKHTIN, 2003).

Entende-se, portanto, que a avaliação da aprendizagem precisa seguir essa perspectiva dialogal e reflexiva para inserir a educação escolar num novo e contemporâneo paradigma. Caso a avaliação da aprendizagem seja dada de forma pré-moldada ou pré-estabelecida, gera-se uma discordância entre as próprias concepções de linguagem e ensino do professor com as práticas que ele mesmo efetua, acarretando o que Alarcão (2001) considera como inadequação da escola para fazer face às demandas da sociedade. A perspectiva classificatória da avaliação, na linha mais tradicional, faz um desserviço para a construção mais plena do saber voltado para a intervenção social e o protagonismo do sujeito. É mister perceber que a verdade é que o sistema classificatório "é tremendamente vago no sentido de apontar as falhas do processo. Não aponta as reais dificuldades dos alunos e dos professores. Não sugere qualquer encaminhamento, porque discrimina e seleciona antes de tudo" (HOFFMAN, 2012, p. 29).

Acreditando que o ato de avaliar a aprendizagem na escola é um meio de tornar os atos de ensinar e aprender produtivos e satisfatórios (LUCKESI, 2011), defende-se a pertinência de se criar um espaço de análise discursiva a respeito de como a avaliação da aprendizagem de língua portuguesa é discutida pela BNCC, para que, por meio de pressupostos teóricos, seja possível investigar como os discursos oficiais se comprometem com os processos de avaliação efetuados nas escolas de educação básica do Brasil. A seguir, apresenta-se a abordagem metodológica do estudo.

\section{METODOLOGIA DA PESQUISA DOCUMENTAL}

Partindo da noção de Linguística Aplicada como uma área de estudo resonsiva e responsável (SILVA JÚNIOR, 2020; AMORIM, 2017), que visa criar inteligibilidades para contextos em que a linguagem tem papel central (MOITA LOPES, 2006; FABRÍCIO, 2006), o estudo segue a abordagem qualitativa de pesquisa, a qual propicia "uma partilha densa com pessoas, fatos, locais que constituem objetos de pesquisa, para extrair desse convívio os significados visíveis e latentes que somente são perceptíveis a uma atenção sensível" (CHIZZOTTI, 2003, p. 221). Nessa abordagem, o pesquisador atua como um sujeito que interpreta diferentes realidades em busca de análises mais fiáveis para implicar mudanças locais e globais.

\footnotetext{
2"O pensamento participativo é uma concepção emocional e volitiva do ser enquanto evento em sua unicidade concreta, sobre a base de um não-álibi no ser, quer dizer, se trata de um pensamento performativo, no sentido de remeter ao eu enquanto ator singularmente responsável pelo ato" (BAKHTIN, 2012, p. 52).
} 
O linguista aplicado, considerado, também, como um pesquisador responsivo (SILVA JÚNIOR, 2020), é um estudioso da linguagem que entende "a vida como um vir a ser e não como um já dado, como uma construção subjetiva coletiva e não como vontade intersubjetiva e, mais ainda, como responsabilidade responsiva e não como um trabalho situado fora de si mesmo" (SOUTO MAIOR, 2013, p. 33). Tal postura, que envolve reflexões e ações de pesquisa, reverbera-se nas mais diferentes vertentes de pesquisa, envolvendo, direta (etnografia, pesquisa colaborativa, pesquisa-ação etc.) ou indiretamente (pesquisa bibliográfica, pesquisa documental etc.), sujeitos da linguagem.

Por se tratar de uma análise de discurso oficial, a pesquisa se insere na vertente documental. Segundo Wolff (2000 apud FLICK, 2009, p. 231), documentos são "artefatos padronizados na medida em que ocorrem tipicamente em determinados formatos". Em vez de usá-los como "contêineres de informação", eles são dispositivos comunicativos, metodologicamente desenvolvidos na construção de "versões sobre eventos" (FLICK, 2009 p. 234). Ainda sobre o objeto de análise deste estudo, Evangelista (2012, p. 61) frisa que:

Documentos são produtos de informações selecionadas, de avaliações, de análises, de tendências, de recomendações, de proposições. Expressam e resultam de uma combinação de intencionalidades, valores e discussões; são construídos pelo e constituintes do momento histórico.

Flick (2009) destaca que quando se decide fazer a análise documental, deve ser levado em conta duas dimensões: se o documento foi solicitado ou não para a pesquisa e se são documentos privados ou públicos. No caso deste estudo, trata-se de um documento não solicitado pela pesquisa e de domínio público.

Distante de uma pesquisa baseada em hipóteses, a investigação documental, ainda, na perspectiva qualitativa da Linguística Aplicada, busca constituir diálogos entre os autores e leitores dos próprios documentos a serem analisados com os autores das pesquisas que os analisam, visando o compartilhamento de ideias por meio do diálogo social. Partindo desses pressupostos, a análise dos dados articula trechos da BNCC que tratam da avaliação da aprendizagem de língua portuguesa com teóricos inseridos nas temáticas apresentadas na abordagem teórica.

\section{AVALIAÇÃo DA APRENDIZAGEM DE LÍNGUA PORTUGUESA NA BNCC}

Lançada em 2018 como um conjunto de reflexões que se agregam em diferentes áreas do currículo escolar, a Base Nacional Comum Curricular (BNCC) para o ensino médio surge como um documento que atualiza e aponta novos horizontes às discussões trazidas pelos Parâmetros Curriculares Nacionais (BRASIL, 1998), bem como pelas Orientações Curriculares 
para o Ensino Médio (BRASIL, 2006). Por ser um documento extenso em termos de estrutura e impactos teórico-pedagógicos, a BNCC destaca olhares para diversas questões que se relacionam com o ensino e a aprendizagem, como a avaliação da aprendizagem, por exemplo, que atua como o foco deste trabalho, em inter-relação com a concepção de língua/linguagem, seguida no desvelar de suas considerações.

Tendo em vista que compreender é dialogar com outros textos e pensar acerca de um novo contexto (BAKHTIN, 2003), depreende-se que um documento direcionador de variadas práticas pedagógicas precisa estar de acordo com as diferentes situações da vida social, as quais são constituídas a partir da reflexão e da crítica do sujeito (BRZEZINSKI, 2001). O texto da BNCC (BRASIL, 2018, p. 7) se define como:

[...] um documento plural e contemporâneo, resultado de um trabalho coletivo inspirado nas mais avançadas experiências do mundo. A partir dela, as redes de ensino e instituições escolares públicas e particulares passarão a ter uma referência nacional comum e obrigatória para a elaboração dos seus currículos e propostas pedagógicas, promovendo a elevação da qualidade do ensino com equidade e preservando a autonomia dos entes federados e as particularidades regionais e locais.

Ao mencionar a questão da autonomia do sujeito e as particularidades regionais e locais, o documento releva a busca de uma concepção dialógica e reflexiva acerca das práticas de ensino, nas quais se inclui a avaliação dialógica da aprendizagem dos alunos, numa perspectiva mediadora. Luckesi (2011) destaca que o processo de avaliação de aprendizagem é sério, pois se está avaliando uma pessoa, um educando, o qual também precisa ser visto como um ser humano, com várias aprendizagens, não só de componentes curriculares preestabelecidos. Uma questão levantada sobre este aspecto é o engano de se pensar que, para conhecer a realidade, é necessário dialogar com todos os alunos, considerando todas as suas perguntas e especificidades. Ora, a perspectiva dialógica não se confunde com o diálogo face a face; trata-se, antes, de uma base teórico-epistemológica de entender o mundo e conceber os sentidos dentro de uma língua que, de acordo com Volóchinov (2017), é viva e está em constante articulação com as práticas sociais. A esse respeito, Hoffman (2012, p.143) assume que a perspectiva dialógica é a:

reflexão crítica sobre as formas como se dá a compreensão do aluno sobre o objeto do conhecimento em questão. O diálogo, entendido a partir dessa relação epistemológica, não se processa obrigatoriamente por meio de conversa, como comunicação verbal com o estudante

Sob um viés mais amplo, esse processo só é propício no contexto de uma escola inovadora, a qual, para Alarcão (2001, p. 19), "é a escola que tem a força de se pensar a partir de si 
própria”, isto é, que não dependa de decisões pedagógicas advindas das redes de vigilância ${ }^{3}$ dos mecanismos de poder (DE CERTEAU, 2009), visto que estas não se preocupam nem um pouco com as relações contextuais e humanas que existem dentro do âmbito escolar, o que remete a uma concepção de avaliação da aprendizagem limitada ao sistema classificatório (HOFFMAN, 2014), que visa apenas a quantificação de notas, que são, sobretudo, redes de segurança (HOFFMAN, 2014). Diferentemente dessa compreensão, a avaliação mediadora busca estabelecer o diálogo vivo entre saberes e entre atores do circuito da aprendizagem, envolvendo tanto o objeto de ensino quanto as relações intersubjetivas.

A própria metodologia, na perspectiva dialógica, pressupõe a construção de um ensino baseado na necessidade de "dizer para o outro" e de "dizer com o outro" (SOUTO MAIOR, 2018). Para as autoras, essas ações são entendidas como resultados de pequenos atos subjetivos/sociais de ser e de agir sobre o outro, e se estabelecem, nos termos de Bakhtin (2003), em relações de alteridade. A noção de alteridade, apresentada por Bakhtin (2003), caracterizada por um processo de transformações de aspectos identitários do sujeito na sua relação com o outro, vincula-se com a citada perspectiva avaliativa por representar o espaço que o professor tem de observar o contexto e fragmentar as suas respectivas práticas pedagógicas, o que contribui para que as inadequações da escola frente à sociedade (ALARCÃO, 2001) sejam reduzidas. O pensamento bakhtiniano oferece, ainda, uma discussão pertinente que compactua com o que se está defendendo sobre avaliação neste estudo, tratando especificamente da questão do racionalismo universal. Nesse sentido, o autor afirma que chega a ser um engano infeliz pensar que a verdade só existe a partir de momentos universais e repetíveis (BAKHTIN, 1993).

Assim, ao se voltar aos acontecimentos recorrentes num dado contexto de ensino e aprendizagem, é inviável que se pense numa verdade ou prática que se repete em diferentes situações. Num processo de ensino e, por consequência, numa prática de avaliação mediadora de aprendizagem, deve-se ter como base o pensamento de que os acontecimentos de sala de aula comumente extrapolam os limites de qualquer previsão plena (SOUTO MAIOR, 2009). Em outros termos, o processo avaliativo, diante do que se destaca nas entrelinhas da BNCC, para o trabalho com a linguagem em sala de aula, está mais direcionado aos sujeitos e ao contexto sociocultural e educacional do que mesmo ao objeto de ensino pré-determinado, mesmo que este tenha importância singular no processo de curricularização do saber. O foco no sujeito e no contexto em que a escola e, por consequência, a sala de aula se inserem leva em consideração das possibilidades de se efetuar práticas de ensino e de avaliação a partir das condições contextuais encontradas no diálogo social (BAKHTIN, 2003; ZOZZOLI, 2016).

A valorização da cultura local e das demais práticas sociais tem sido um ponto decisivo para o desenvolvimento de práticas de ensino que contribuam para uma aproximação direta entre linguagem e escola como perspectivas sociais (SOARES, 2001). As interações que

${ }^{3}$ Redes de vigilância são forças representadas pelas relações de poder social que direta ou indiretamente ditam padrões normativos a serem exercidos pelos sujeitos em termos locais e globais. 
ocorrem em sala de aula são importantes tanto para que o aluno possa integrar mais efetivamente as atividades pedagógicas como para que o professor possa observar as respostas ativas (BAKHTIN, 2003) dos alunos e, a partir delas, criar seus respectivos meios de avaliar o processo de aprendizagem, o que não ocorre a partir de ações pré-moldadas pura e simplesmente, mas, sim, a partir de acontecimentos não totalmente previsíveis e sempre baseados nas relações entre os sujeitos nas salas de aula.

Tavares (2001, p. 35), a esse respeito, compreende que as relações interpessoais "terão de funcionar nos dois sentidos e ser incondicionalmente positivas. Ou seja, as duas ou mais pessoas envolvidas na relação deverão reconhecer-se, afirmar-se, aceitar-se e confirmar-se de modo positivo e condicional", para uma dinâmica mais ampla no espaço social. Complementando a discussão sobre interação, relações interpessoais e as práticas avaliativas em sala de aula, a BNCC (BRASIL, 2018, p. 477) aponta que as demandas sociais vêm:

possibilitar aos estudantes condições tanto para o adensamento de seus conhecimentos, alcançando maior nível de teorização e análise crítica, quanto para o exercício contínuo de práticas discursivas em diversas linguagens. Essas práticas visam à participação qualificada no mundo, por meio de argumentação, formulação e avaliação de propostas e tomada de decisões orientadas pela ética e o bem comum.

No fragmento em tela, a avaliação se apresenta qualitativamente quando se destacam pontos como: a participação qualificada do sujeito, as decisões orientadas, a ética e o bem comum. Mesmo que muitas práticas avaliativas de sala de aula possam parecer mecânicas e travadas a partir de instrumentos estáticos, numa perspectiva dialógica elas são visualizadas sob um viés diferente, visto que precisam acompanhar a dinâmica que o ensino de língua portuguesa se coloca de modo concreto e processual, pois há qualificadores das ações a serem observadas (participação que não é qualquer uma, mas sim uma "qualificada"; decisões que não são aleatórias, mas, antes, "orientadas"; ética e bem comum). Esse modo dialógico de se pensar a avaliação da aprendizagem pode ser um significativo veículo para desconstruir práticas avaliativas que se prendem ao que Luckesi (2008) chama de pedagogia do exame. Ao tratar de participação qualificada, a BNCC deixa claro que a participação na sala de aula não deveria se dar de qualquer forma. É essencial que exista, segundo a proposta, uma postura crítica desse sujeito nas atividades de ensino, acarretando práticas avaliativas, elaboradas pelo professor em consequência da sua observação sensível, mais coerentes com o contexto e respondendo ativamente (BAKHTIN, 2003) às demandas da contemporaneidade para a educação escolar brasileira.

Nessa linha de pensamento, num documento direcionador e auxiliar das práticas de ensino de língua portuguesa como a BNCC, depreende-se que a observação crítica do professor sobre a sua prática propiciaria uma revisão de bases teóricas e estimularia continuidades de 
discussões/teorias já colocadas dentro das pesquisas que intentam refletir acerca do trabalho com a língua portuguesa em sala de aula, o qual não se resume em memorização das normas de estrutura da língua, mas que, numa perspectiva discursiva, retomam temas da vida social, como o bem comum e a ética. A reflexão sobre a avaliação que leva em consideração esses aspectos transforma o contexto de ensino num local de produção e materialização de sentidos pelo discurso (MIOTELLO, 2014), ou seja, uma arena responsiva (SILVA JÚNIOR, 2021) na qual discursos se intercruzam para que a avaliação da aprendizagem não seja mais um dos equívocos presentes nas ações de ensinar e aprender a língua portuguesa (SABER, 2012).

Assim, as atitudes éticas levam em consideração os diferentes fatores que cruzam os acontecimentos de sala de aula, mediados, sobretudo, pela linguagem. Nesse sentido, na ênfase dada ao bem comum, a BNCC se aproveita, no ensino de língua portuguesa, das diversas questões valorativas que se agregam à constituição dos sujeitos, concordando, dessa maneira, com o que consideram Volóchinov e Bakhtin (1926), quando dizem que viver significa ocupar uma posição de valores em cada contexto de atuação social. As posições valorativas do/s sujeito/s reiteram o processo alteritário que ocorre nas atividades pedagógicas e proporcionam possíveis momentos para o professor de língua portuguesa (re)pensar e teorizar sua prática levando em conta a produção de novos significados para as práticas avaliativas e não somente o recebimento de significados (SABER, 2009) prontos.

Além disso, quando se trata de decisões orientadas, a BNCC evidencia o foco no outro, dado pelas práticas pedagógicas no ensino de língua portuguesa. Nesse contexto, dada a compreensão de que, em sala de aula, os processos de alteridade (BAKHTIN, 2003) são constantes por revelarem os impactos da interação dialógica, numa avaliação mediadora, entre os sujeitos nas suas próprias constituições identitárias, entende-se que as decisões orientadas correspondem aos meios pelos quais o professor se utiliza da sala de aula para criar espaços reflexivos com os alunos e, através disso, (re)moldar as ações avaliativas ${ }^{4}$ (PRAXEDES, 2018) mais propícias para a/s situação/ões identificada/s.

Desta feita, observa-se que o processo avaliativo, mediado por essas considerações, é capaz de solidificar os modos com os quais os alunos compreendem a própria estadia na escola e a interação com os demais sujeitos, uma vez que, de acordo com Alarcão (2001, p. 19), na escola tem sido "preciso envolver o elemento humano, as pessoas e, através delas, mudar a cultura que se vive na escola e que ela própria inculca" no dia-a-dia. O elemento humano, mencionado pela autora supracitada, lembra a concepção de Bakhtin (1993) sobre o Ser único, pois, mesmo que as relações dialógicas na/da vida social estejam em constante processo de articulação entre a consciência psíquica e o mundo exterior, o momento em que ocorre

\footnotetext{
${ }^{4}$ As ações avaliativas consistem em práticas pedagógicas planejadas sistematicamente no intuito de contribuir para um aproveitamento mais significativo do processo de aprendizagem dos alunos. A pluralidade colocada no termo "ações" já evidencia a diversidade de ações que podem ser formuladas.
} 
a enunciação promove e reflete a subjetividade dos sujeitos envolvidos no diálogo e implica novas ações desses sujeitos.

Vasconcelos (2005, p. 25) considera que "para mudar a avaliação não basta articular um discurso novo; não adianta ter uma nova concepção e continuar com práticas arcaicas”. A avaliação mediadora, dentro de uma abordagem dialógica de ensino, atua como um veículo relevante para que o aluno perceba o quanto a sua participação ativa nas práticas pedagógicas pode implicar positivamente o seu processo de aprendizagem, especialmente de língua portuguesa, acarretando uma possível desmistificação de concepções tradicionalistas nas quais a avaliação se limita ao que se denomina prova. Silva Júnior (2018b) complementa essa reflexão destacando que é emergencial a necessidade de se fugir de concepções e práticas tradicionalistas, considerando que, somente assim, a sala de aula pode se tornar um espaço amplo no qual se possa trabalhar não apenas a língua, mas a linguagem em sua totalidade, isto é, uma arena responsiva (SILVA JÚNIOR, 2021).

A BNCC aponta para a necessária visão processual de ensino de língua portuguesa, quando as habilidades requeridas no ensino médio partem do que o aluno já precisa ter aprendido durante o ensino fundamental. A avaliação da aprendizagem se coloca num paradigma ainda mais autônomo e propício à reflexão consciente do sujeito da linguagem, como se pode ver a seguir:

[...] o foco maior nas habilidades envolvidas na reflexão sobre os textos e práticas (análise, avaliação, apreciação ética, estética e política, valoração, validação crítica, demonstração etc.), já que as habilidades requeridas por processos de recuperação de informação (identificação, reconhecimento, organização) e por processos de compreensão (comparação, distinção, estabelecimento de relações e inferência) já foram desenvolvidas no Ensino Fundamental (BRASIL, 2018, p. 491).

As práticas avaliativas do ensino de língua portuguesa no nível médio, conforme consta no fragmento apresentado, enfatizam a necessidade de o professor desenvolver atividades que possam estimular ainda mais a habilidade crítica de alunos que já passaram pelo ensino fundamental. Assim, a observação dos processos de responsividade - compreensão e atitude responsivas ativas (BAKHTIN, 2003) - que ocorrem em sala de aula, além de implicar a percepção do professor sobre os resultados de sua prática, propiciam a observação de como o ensino fundamental preparou os alunos durante os 8 (oito) anos antecedentes. Todo esse processo contribui para reflexões e possíveis reelaborações de práticas pedagógicas a depender do que o professor identifica no seu contexto de trabalho, uma vez que a "avaliação da aprendizagem deve apontar para a construção de uma prática avaliativa qualitativamente mais significativa, comprometida com a aprendizagem" (FURLAN, 2007, p. 20) do sujeito. 
Complementando essa discussão, a BNCC (BRASIL, 2018, p. 512) assinala que o aluno do ensino médio precisa:

Analisar formas contemporâneas de publicidade em contexto digital e peças de campanhas publicitárias e políticas (cartazes, folhetos, anúncios, propagandas em diferentes mídias, spots, jingles etc.), explicando os mecanismos de persuasão utilizados e os efeitos de sentido provocados pelas escolhas feitas em termos de elementos e recursos linguístico-discursivos, imagéticos, sonoros, gestuais e espaciais, entre outros, e destacando valores e representações de situações, grupos e configurações sociais veiculadas, a fim de desconstruir eventuais estereótipos e proceder a uma avaliação crítica da publicidade e das práticas de consumo.

Os objetivos de aprendizagem mencionados mostram indícios de que o processo de avaliação de aprendizagem dos alunos na sala de aula de língua portuguesa no ensino médio não pode ser vinculado aos procedimentos tradicionais, que funcionam mais como testes do que mesmo como avaliações, acreditando que tudo gira em torno de respostas pré-determinadas. A exploração das modalidades de linguagem e das representações que norteiam as práticas sociais remete ao entendimento de que, em termos de ensino e aprendizagem, a avaliação deve criar a possibilidade de abrir espaço para diferentes relações (LUCKESI, 2011) a partir da interação, como: de aceitação, de negociação e de redirecionamento.

Levando em consideração o que foi pontuado, depreende-se que a BNCC para a língua portuguesa no ensino médio pode estar no escopo de uma concepção de língua/linguagem defendida pelos representantes dos estudos dialógicos da linguagem, no que concerne à avaliação da aprendizagem dos sujeitos em sala de aula. Isso porque, da maneira em que se consideram as diferentes habilidades que podem ser estimuladas em sala de aula e a perspectiva processual em que o ensino se insere, as concepções de linguagem e de ensino do professor, a partir de um documento direcionador, giram em torno do termo "reflexão", o qual, neste estudo, possui uma extensa carga semântico-discursiva por abrir os horizontes da noção de avaliação da aprendizagem de uma língua materna, defendendo, sobretudo, que o que contém na língua portuguesa não se resume a um conjunto de regras estanques, mas, sim, a uma riqueza linguístico-discursiva que precisa ser aproveitada nas ações de sala de aula.

\section{CONSIDERAÇÕES FINAIS}

Por estar inserido no campo crítico e híbrido da Linguística Aplicada, o qual "propicia o desenvolvimento de inquietações diversas para problematizar o que está posto" (SILVA JÚNIOR, 2018a, p. 109), este trabalho, de natureza documental, não buscou criar soluções ou 
respostas para problemas precedentes, mas constituir um espaço de discussão a respeito de um tema que estará sempre em destaque quando se pensa sobre o ensino de língua portuguesa - a avaliação da aprendizagem, a partir de um documento direcionador para o trabalho com a linguagem em sala de aula, como a BNCC (BRASIL, 2018) para o ensino médio.

Mesmo que a estrutura do documento não comporte um momento específico para o tratamento da avaliação da aprendizagem, foi possível indicar fragmentos que deixam pistas de como a BNCC (BRASIL, 2018) aborda esse processo, o que enfatizou a relevância de leituras críticas na pesquisa acadêmica sobre os documentos norteadores. Termos como: autonomia, análise crítica, decisões orientadas, compreensão, valores e configurações sociais foram basilares para que as práticas avaliativas defendidas pela BNCC (BRASIL, 2018) pudessem ser identificadas, evidenciando a importância de denominar esse processo como avaliação mediadora, dentro de uma abordagem dialógica de ensino.

Nesse sentido, a concepção dialógica da linguagem esteve presente nas discussões por ser a que mais se aproxima das discussões ressaltadas pela leitura da BNCC. A noção de alteridade propiciou uma reflexão sobre como o sujeito (professor e/ou aluno) é impactado por meio das reflexões estabelecidas nas relações dialógicas em práticas avaliativas de sala de aula, sendo complementadas com a discussão a respeito da razão teórica, da razão prática e do Ser único no acontecimento social.

Cabe ainda ressaltar o necessário olhar para os docentes no que se refere ao trabalho com a língua portuguesa no ensino médio, tendo como documento norteador a BNCC. É preciso, sobretudo, de uma "formação de professores eficiente, a qual frutifique sujeitos críticos para a interconstituição dentro e fora do espaço da sala de aula" (SILVA JÚNIOR; SANTANA, 2019, p. 65), reiterando, com isso, o compromisso social da instituição de ensino de preparar sujeitos para refletirem e agirem conscientemente nas diferentes práticas cotidianas.

Ao propor pluralidades, contemporaneidade experiências de mundo, a BNCC, desde a sua caracterização, já coloca o processo de ensino de língua portuguesa e as consequentes ações avaliativas no seio de uma perspectiva dialógica de linguagem e de ensino. Espera-se que o presente trabalho possa estimular a reflexão de professores-pesquisadores a respeito das temáticas da avaliação da aprendizagem no ensino de língua portuguesa e da BNCC linguagens e suas tecnologias numa perspectiva mais ampla.

\section{REFERÊNCIAS}

ALARCÃO, I. Professores reflexivos em uma escola reflexiva. São Paulo: Cortez, 2011.

ALARCÃO, I. A Escola Reflexiva. In: ALARCÃO, I. (Org.) Escola reflexiva e nova racionalidade. Porto Alegre: Artmed Editora, 2001. p. 15-30. 
AMORIM, M. A. A linguística aplicada e os estudos brasileiros: (inter-)relações teóricometodológicas. Revista Brasileira de Linguística Aplicada, v. 17, p. 1-30, 2017.

BAKHTIN, M. Para uma filosofia do ato responsável. Tradução: Valdemir Miotello e Carlos Alberto Faraco. 2. ed. São Carlos: Pedro \& João Editores, 2012.

BAKHTIN, M. Estética da criação verbal. Tradução: P. Bezerra. 4. ed. São Paulo: Martins Fontes, 2003.

BRASIL. SNEB. Base Nacional Comum Curricular: Língua Portuguesa. Brasília: MEC, 2018.

BRASIL. SNEB. Orientações Curriculares Nacionais para o Ensino Médio: Língua Portuguesa. Brasília: MEC, 2006.

BRASIL. SNEB. Parâmetros Curriculares Nacionais: Língua Portuguesa. Brasília: MEC, 1998.

BRZEZINSKI, I. Fundamentos Sociológicos, Funções Sociais e Políticas da Escola Reflexiva e Emancipadora: Algumas Aproximações. In: ALARCÃO, I. (Org.) Escola reflexiva e nova racionalidade. Porto Alegre: Artmed Editora, 2001. p. 65-82.

CARMINATTI, S. S.; BORGES, M. K. Perspectivas da avaliação da aprendizagem na contemporaneidade. Estudos em avaliação educacional. São Paulo, v. 23, n. 52, p. 160-178, maio/ago. 2012.

CHIZZOTTI, A. A pesquisa qualitativa em ciências humanas e sociais: evolução e desafios. Revista Portuguesa de Educação, v. 16, n, 2, p. 221-236, 2003.

DE CERTEAU, M. A invenção do cotidiano. 7. ed. Tradução: Ephraim Ferreira Alves. Petrópolis: Vozes, 2009.

EVANGELISTA, O. Apontamentos para o trabalho com documentos de política educacional. In: ARAÚJO, R. M. L.; RODRIGUES, D. S. (Org.) A pesquisa em trabalho, educação e políticas educacionais. Campinas, SP: Alínea, 2012, p. 52-71.

FABRÍCIO, B. F. Linguística aplicada como espaço de desaprendizagem: redescrições em curso. In: MOITA LOPES, L. P. (Org.). Por uma linguística aplicada INdisciplinar. São Paulo: Parábola, 2006. p. 45-65.

FLICK, U. Desenho da pesquisa qualitativa. Porto Alegre: Artmed, 2009.

FLICK, U. Uma introdução à pesquisa qualitativa. Porto Alegre: Artmed, 2004.

FURLAN, M. I. C. Avaliação da aprendizagem escolar: convergências, divergências. São Paulo. Amablume editora, 2007.

GOERGEN, P. A avaliação universitária na perspectiva da pós-modernidade. Avaliação: Revista da Avaliação da Educação Superior, ano 2, v. 2, n. 3, p. 53-66, set. 1997. 
LIMA, A. C. S.; SOUTO MAIOR, R. C. Responsividade e Discursos Envolventes: observando o ensino e aprendizagem de Língua Portuguesa. Eutomia, v. 02, p. 394-413, 2012.

LUCKESI, C. C. Avaliação da aprendizagem: componente do ato pedagógico. São Paulo: Cortez, 2011.

MIOTELLO, V.; Grupo de Estudos de Gêneros do Discurso - GEGE (Org.) Conversa com os mitos. 1. ed. São Carlos: Pedro \& João Editores, 2014.

MOITA LOPES, L. P. Linguística Aplicada e Vida Contemporânea: problematização dos construtos que têm orientado a pesquisa. In: MOITA LOPES, L. P. (Org.) Por uma linguística aplicada indisciplinar. São Paulo: Parábola, 2006.

PRAXEDES, A. L. S. As ações avaliativas no Pibid/Letras - Português: um componente pedagógico tático na construção do conhecimento. Monografia (Graduação em Letras - Língua Portuguesa) - Faculdade de Letras, Universidade Federal de Alagoas, 2018.

SILVA JÚNIOR, S. N. Dialogismo e auto-observação em práticas linguístico-discursivas com a língua portuguesa no ensino superior: a sala de aula como arena responsiva. Tese (Doutorado em Linguística) - Faculdade de Letras, Universidade Federal de Alagoas, 2021.

SILVA JÚNIOR, S. N. Ação docente responsiva ativa e pesquisa de auto-observação na perspectiva da linguística aplicada. Leitura. Revista do Programa de Pós-Graduação em Letras (UFAL), v. 2, p. 375-388, 2020.

SILVA JÚNIOR, S. N. Produção oral sistematizada em atividades didáticas de língua portuguesa: um trabalho colaborativo no ensino fundamental. Dissertação (Mestrado em Linguística) - Faculdade de Letras, Universidade Federal de Alagoas, 2019.

SILVA JÚNIOR, S. N. Aspectos da linguística aplicada para a formação do pesquisador. Linguagem: Estudos e Pesquisas, v. 22, p. 109-127, 2018a.

SILVA JÚNIOR, S. N. O uso de táticas no trabalho com o livro didático de língua portuguesa: constituindo práticas reflexivas de letramento. In: PAIVA, F. J. O; SILVEIRA, E. L. (Orgs.). O ensino na educação básica: diálogos entre sujeitos, saberes e experiências docentes. São Carlos: Pedro e João Editores, 2018b, p. 37-60.

SILVA JÚNIOR, S. N.; SANTANA, W. K. F. Língua oral e língua escrita: a constituição do sujeito dialógico nos PCN de Língua Portuguesa. Revista Interfaces, v. 10, p. 55-66, 2019.

SOARES, M. Linguagem e escola: uma perspectiva social. São Paulo: Ática, 2001.

SOUTO MAIOR, Rita de Cássia. Ética discursiva em tempos sombrios: linguagem e sentidos. In: SOUTO MAIOR, R. C. et al. (Org.). Estudos discursivos das práticas de linguagem. Tutoia: Diálogos, 2020. 
SOUTO MAIOR, R. C. Pensamento bakhtiniano nos estudos da linguagem: a ação do pesquisador como ato responsável. Polifonia: Estudos da Linguagem, v. 20, p. 31-53, 2013.

SOUTO MAIOR, R. C. Os saberes docentes e as constituições de Ethos de licenciandas/os no Programa de Iniciação à Docência/Letras-Português: análise das implicações dos discursos envolventes e a necessária inscrição de uma ética do discurso. In: FIGUEIREDO, F. J. Q.; SIMÕES, D. (Orgs.). Contribuições da Linguística Aplicada para a educação básica. Campinas, SP: Pontes, 2018, v. 1, p. 133-185.

SOUTO MAIOR, R. C. As constituições de Ethos e os Discursos Envolventes no Ensino de Língua Portuguesa em Contexto de Pesquisa-ação. Tese (Doutorado em Linguística) Faculdade de Letras, Universidade Federal de Alagoas, 2009.

TAVARES, J. Relações Interpessoais em uma Escola Reflexiva. In: ALARCÃO, I. (Org.) Escola reflexiva e nova racionalidade. Porto Alegre: Artmed Editora, 2001. p. 31-64.

VASCONCELLOS, C. S. Avaliação da aprendizagem: práticas de mudanças - por uma práxis transformadora. 7. ed. São Paulo. Libertad. 2005.

VOLÓCHINOV, V. Marxismo e filosofia da linguagem: Problemas fundamentais do método sociológico na ciência da linguagem. Tradução: Sheila Grillo e Ekaterina Vólkova Américo. São Paulo: Editora 34, 2017.

VOLÓCHINOV, V; BAKHTIN, M. Discurso na vida e discurso na arte: sobre poética sociológica. Tradução: Carlos Alberto Faraco; Cristóvão Tezza [para fins didáticos]. 1926. Versão da língua inglesa: I. R. Titunik a partir do original russo.

ZOZZOLI, R. M. D. Transdisciplinaridade e plurivocidade. In: SOUTO MAIOR, R. C. et al. (Orgs.). Estudos discursivos das práticas de linguagem. Tutoia: Diálogos, 2020, p. 619-631.

ZOZZOLI, R. M. D. Levando o diálogo social para a sala de aula: o enunciado-acontecimentotema no ensino de língua portuguesa. In: FIGUEIREDO, F. J. Q.; SIMÕES, D. (Orgs.) Linguística Aplicada, prática de ensino e aprendizagem de línguas. Campinas, SP: Pontes Editora, 2016. p. 135-156.

ZOZZOLI, R. M. D. Leitura e produção de texto: teorias e práticas na sala de aula. Leitura, Maceió, v. 21, 1998.

Recebido para publicação em: 18 abr. 2021.

Aceito para publicação em: 20 jul. 2021. 